\title{
"APPLE"Ad or not Ad: That is the Question
}

\section{Mert Avan (Turkey)}

Doi:10.5901/ajis.2013.v2n8p222

Saint-Petersburg State University, School of journalism and mass communications, Student

\section{Abstract:}

Someone stop the "Apple"! I want to ask, how many of you own an Apple product right now or used one before? I'm sure that the number will not be few. Well, let's take a look at the reason why. Quality, design, social pressure, just fashion or maybe another thing but advertising is not in the first place for sure. Or let's say this; nobody runs into the first electronic store at the corner after watching a creative commercial. Apple; our favourite April Fools At the 1st of April 1976, Apple has been born like a little joke with huge effects beneath. In years it has became a joke that gets bigger and bigger inside. At the present time i will not bother explain the word to you but I can say that, we laughed at that joke so hard that we have been laughing at it for 37 years, sadly it makes us cry sometimes. Don't fire us "Apple"! This tasty company takes a role in our lives with simple but effective ads. Actually they do not need too much ads on nowadays. Maybe that's why they are following their recent path. But how long will it go on like this? Before talking about this I would like to mention about Steve Jobs. He made so many things and said so many words in so many various areas but in the essence of the matter he said "Think different!" via Apple Company. I don't know if we could have thought as he said or not but we took a bite from his 'apple' as he wanted to. We have to urge on that he spoke to us as himself without any middlemen or an agent. We can not ignore that despite he is a modern technology genius and a chairman of a big company, he is also a really successful PR and maybe a promoter too. Besides the simplicity of his adverts, his talents of mass controlling, management and addressing took an important role in where the 'Apple' today. Because 'presentation comes before advertising' is exactly used in its meaning. There is a word about it; the person who can present a fruit best is the owner of its garden, nevertheless he was the owner as he was the worker at in this copious garden. Also not mentioning about his good looking and attraction will not be fair when it comes to gloss. All over the world when it's asked, how many of chairmen in information technologies will be remembered as significantly as him? Not many. However tragically, he passed away so young. Can Apple walk on its path in long term? In my opinion it is highly unlikely. Think about the opposite, what if all major companies follows the Apple's path and kill the creative advertising day by day? I am not on this 'advertising road' to serve a world like this. One of the most rapidly changing thing fashion, will have no mercy on Apple too. Right now they are on a locomotive and speed up every single day but I am not sure that the steam will be enough for another 37 years. How long a company which repeats itself with tiny little changes can stay on its path? Apple, I am calling you. It is time to take the arm that named creative advertising or the time will come in near future because you do not have a second Steve Jobs. Apple is not forbidden anymore There's been said Apple's logo comes from Adam and Eve and the bite referred to Alan Turing. An apple sets off the entire human history and so to say another apple carries it into another dimension. Now it is a sin that not tasting from this apple or it is still forbidden and no one can stand the pleasure and ease. Now I am asking to you; Another bite?

\section{Someone make the "Apple" stop.}

I need to ask; How many people owns a Apple Product or used one? It is obvious that figures are not few. And now let's take a look at the reasons. Is it quality ? Is it design? Is it trend or social pressure ? Maybe the real reason is not told in this article but we do know the fact that it is not the advertisement. Well, to be precise ; no one runs to an electronics store after watching a creative TV commercial.( Of course there are exceptions.)

\section{Our favorite April Fools Day Joke "Apple"}

In first of April at 1976 "Apple" was born as a teeny tiny but effective joke, and within years this joke kept getting bigger and larger. Today, I don't think I need to explain the meaning behind this word, however I can say; We loved this joke so much, we are still laughing and crying together after 37 years.

\section{3. "Do not make us unemployed "Apple"."}

This pretty company is in our life with its simple but effective ads. Actually it does not need any advertisement anymore. Maybe this is why it decided to go this way. 
Well, first we need to have a look at the history ; Apple introduced the "Apple Macintosh" with the famous 1.5 million dollar budged "1984" TV Commercial. The Commercial directed under the Ridley Scott

took air at the third quarter of Super Bowl XVII at 22 of October 1984.

-This event is considered the corner stone of its success- And it is stated that it was one of the masterpieces in advertisement history. Some people acknowledge this advertisement as the most famous and some acknowledge it as the best advertisement of all times...( for me personally I named it as the "die Ad".)

*The one who created the ad was the Chiat/day Agency. Agency's head Lee Clow made the Rabbit of Energizer and Taco Bell's Chihuahua advertisement campaigns after the "die ad".

- Even the "die Ad" was aired once in the national TV , it was aired in a Local TV Chanel in Twin Falls Idaho in $15^{\text {th }}$ of December 1983, participating in the 1983 Advertisement Awards. Afterwards with the week starting with $17^{\text {th }}$ of October (1984), "die Ad" was screened in theaters.

- Even with its narrowed screening "die Ad" has created a massive media madness . According to Nielsen Ratings "die Ad"'s views rate at the Super Bowl was 46,4\%. ( male viewers rate $50 \%$, female viewers rate $36 \%)$

- These figures and tactics made the "die ad" the first example of Events Marketing.

- Also "die Ad" has triggered and shaped today's Super Bowl advertisement's madness.

- The woman who throws the hammer to big brother in the "die Ad" was Anya Major. (she was an athlete and a model.) Big Brother was acted by the David Graham and the outer voice at the end of the "die ad" belongs to Edward Grover. ( my personal opinion is his voice is really similar to Malcolm McDonnell's voice.)

- "die Ad" also conquered a huge spot inside of the Popular Culture. 84 $4^{\text {th }}$ minute of the movie titled "Fight Club" shows as one of the events of Project Mayhem ; an Apple Macintosh computer being shattered into pieces.

- A TV Animation Series called "Futurama" made a advertisement parody in a episode named "Future Stock" in its 3.season.

- Inside of the video game named "Grand Theft Auto Vice City Stories" one of the radio channel has a "Fruit Ic" ad and this ad is directly a 1984 parody.

- Barack Obama's campaign in 2006 is exactly the copy of "die Ad" and one of the few differences between 2006 's copy campaign was Big brother. It has showed as the Hilary Clinton.

As you see an incredible "start". Effective, impressive, creative and ambitious.

Year 1997 and the time has come to the Ad that made me write this article, that Ad was yelling at my face as "Steve Jobs is back.". That Ad "Think Different".( and for me it was the breakthrough of my destiny , after years I understood and named this ad in my mind with simple two words "M-Ad". The "M" was there with the meaning of mentor.)

I remember when I watched the ad of my lifefor the first time. It mesmerized me within seconds.M-Ad was showing to me people who were breaking the realms chains and that moment my decision has been made. I said to myself in my inner thoughts "I am gonna be an advertiser".

M-Ad shows that there is no boundaries to mankind's capacity, in the same time M-Ad tells me that a advertiser has to erase all the boundaries and has to remove all the limiters and M-Ad was encouraging this idea. At least that was what I understood and this was the what was important.

But unfortunately "Apple" started to fall and this fall is not in a good way. Apple changed its direction to a darker and scarier way and again, unfortunately there is no technology that can light this way and show the greatness they showed in the past.

\section{So How Long They will be able to go on?}

Before starting to talk about this topic , I wanna talk a little about Steve Jobs. He did lots of thing in many different areas, he said lots of things in many different topics however he told us with a tool named "Apple" - "Think Different". I do not know if we did or didn't but I know we all did what he wanted us to do and bit the apple without a second thought. Well, I have the feeling that we have to take a closer look at the reason why he said this to the world. We can't deny that he is not just a genius on modern world technologies in the same time he is a great $\mathrm{Pr}$ and probably one of the most creative advertiser of $21^{\text {th }}$ century. One of the elements of Jobs is the solid and never changing plain and simple design and again we can't deny that his global manipulation talent is the main reason of the status of "Apple" in now a days. - Person who knows the apple best is the owner of the apple- And jobs wasn't only the owner, he was the gardner of this productive farm. Of course not talk about its beauty would be a disgrace. Around the world, how many of technology companies founders are known by people? I do not know the exact number but I am sure it's just a few and unfortunately he left this 
world and us in a really young age.

\section{5. "Can Apple go further ?"}

My personal opinion is its not gonna happen however think a world goes in the opposite direction of my thought system; other big firms goes in the same direction of "Apple and this kind of path slowly kills the creative advertisement day by day. I did not choose the advertisement sector for serving this kind of world system.

I think the thing called fashion shift won't have any mercy to the apple .At the present its has this trend and continues its marketing by this trend however can it continue an other 37 years like this. A firm which repeats its self by little variations, how long can it keep its self before crumbling.

Kan Segal says in the book named "Insanely Simple"; Apple started to walk a way without human source in fact we can say Apple's advertisement's source are their product. With out a doubt , I agree with this thought and Apple ads are getting further away from creative advertisement day by day.

\section{That Era has ended long ago ! Apple , WAKE UP !}

In today's market, advertisement does not have the echo it should has, and main cause of this is global market has growth a lot and changed a lot, variations increased with the competition. Creating the right attention is no more a tool, now it is a must for companies. First of all we should understand this, people in this world which understands the small differences between the technologies are few than people who doesn't understand those differences. Instead of reaching the target audience, why not collect all the mass appeal in one place?

This has been done before and can be done again. At first "Apple" wanted us to "Think Different" but now it started to became one of the stereotype firm....

Apple! I am calling and telling you; You have to take the gun named "creative advertisement" one more time and that time is really soon because you no more have an ammo named "Steve Jobs".

\section{Apple is No more a "Sin"}

It is said that Apple's logo's origin is widely known; Adam and Eve's apple, forbidden fruit.

(Some people say its logo is for the respect of Alan Turing.) And I wanna ask you in the end of my article one more time;

One A Bite Just one time?

A Bite from apple started the mankind's history

Second bite brought the evolution

Third Bite is a known human's mystery

And book lies biting is no more a sin

How could someone can say no

To its mesmerizing taste

And now I ask you one more time

Do you want one more bite 